Running head: OVERQUALIFICATION

\title{
Too Good for Your Job? Disentangling the Relationships Between Objective Overqualification, Perceived Overqualification, and Job Dissatisfaction
}

\author{
Maryana L. Arvan, Shani Pindek, Stephanie A. Andel, and Paul E. Spector
}

\section{Author Affiliations and Contact Information}

\begin{tabular}{|l|l|}
\hline Maryana L. Arvan, M.A. & Shani Pindek, Ph.D. \\
Doctoral Candidate & Assistant Professor \\
Department of Psychology & Department of Human Services \\
University of South Florida & University of Haifa \\
4202 E. Fowler Ave., PCD 4118G & 199 Abba Hushi Blvd \\
Tampa, FL 33620 & Haifa, Israel, 3498838 \\
msheroiansan @mail.usf.edu & shanipindek@ mail.usf.edu \\
813-974-2492 & 972 54-4929229 \\
& \\
\hline Stephanie A. Andel, Ph.D. & Paul E. Spector, Ph.D. \\
Assistant Professor & Distinguished Professor \\
Department of Psychology & Department of Psychology \\
Indiana University-Purdue University & University of South Florida \\
Indianapolis & 4202 E. Fowler Ave., PCD 4118G \\
402 N. Blackford Street & Tampa, FL 33620 \\
Indianapolis, IN 46202 & pspector@ usf.edu \\
sandel@iu.edu & 813-974-0357 \\
& \\
\hline
\end{tabular}

This is the author's manuscript of the article published in final edited form as:

Arvan, M. L., Pindek, S., Andel, S. A., \& Spector, P. E. (2019). Too good for your job? Disentangling the relationships between objective overqualification, perceived overqualification, and job dissatisfaction. Journal of Vocational Behavior, 103323. https://doi.org/10.1016/j.jvb.2019.103323 


\section{Funding}

This research was funded by the University of South Florida. 
Too Good for Your Job? Disentangling the Relationships Between Objective Overqualification, Perceived Overqualification, and Job Dissatisfaction

Keywords: overqualification; job satisfaction; person-environment fit theory 


\begin{abstract}
In the present study, we investigated the relationships between objective overqualification, perceived overqualification, and job satisfaction based on the tenets of P-E fit theory, a commonly-used theoretical framework in the overqualification literature. Specifically, we tested whether employee perceptions of overqualification mediate the relationship between objective overqualification and job dissatisfaction. Results across two studies indicated that objective overqualification and job satisfaction independently predicted perceived overqualification, which contradicts the prevailing view in the literature of unidirectional effects between overqualification and strain outcomes. Study 1 used a cross-sectional survey of recent college graduates to test the overall mediation model. Although the model was supported, the relationship between objective overqualification and job satisfaction was not significant, raising the question of whether the hypothesized predictive relationship between perceived overqualification and job satisfaction is reversed. Study 2 tested directionality in the relationship between perceived overqualification and job satisfaction using a three-wave longitudinal panel design in a sample of full-time university staff employees. Results indicated that job dissatisfaction predicts subsequent perceived overqualification rather than the reverse.
\end{abstract}


In the aftermath of the 2008-2012 global financial crisis and the tortuous road to economic recovery, scholars have increasingly focused on individuals who find themselves in less-than-desirable employment situations (Liu \& Wang, 2012; McKee-Ryan \& Harvey, 2011). Overqualification is a specific kind of inadequate employment that occurs when employees have more qualifications, such as education or experience, than required by their jobs (Erdogan, Bauer, Peiro, \& Truxillo, 2011; Maynard, Joseph, \& Maynard, 2006). Overqualification is significant in that it is perceived negatively by hiring managers and may act as a barrier to employment (Erdogan et al., 2011; Maynard, Taylor, Hakel, 2009). Especially concerning to organizational researchers is the growing body of evidence that overqualification can have deleterious effects on employees and the organizations who employ them, particularly if the overqualification is perceptual in nature (i.e., self-reported). Indeed, a recent meta-analysis found that perceived overqualification is related to poorer job attitudes and well-being, and greater turnover intentions (Harari, Manapragada, \& Viswesvaran, 2017).

Being an area of relatively new interest to organizational scholars, theoretical and measurement-related issues abound in recent reviews on overqualification (e.g., Erdogan et al., 2011; Liu \& Wang, 2012). First, there are mixed findings on overqualification and theoretically relevant outcomes. On the one hand, consistent with person-environment fit (P-E) theory (Kristof-Brown, Zimmerman, \& Johnson, 2005), the link between perceived overqualification and attitudinal and psychological strain outcomes is fairly well-established (Harari et al., 2017). On the other hand, perceived overqualification does not significantly relate to task performance or organizational citizenship behaviors (OCBs;Harari et al., 2017). These inconsistencies raise the question of whether P-E fit theory is an appropriate theoretical framework to explain the effects of overqualification (Erdogan et al., 2011; Liu \& Wang, 2012). 
Second, there is a lack of clarity on the association between objective and subjective overqualification, and their respective relationships with criteria of interest. Consistent with P-E fit theory, most researchers assume that perceptions of overqualification mediate the relationships between objective overqualification and outcomes (Liu \& Wang, 2012; Luksyte \& Spitzmueller, 2011). However, this assumption has been rarely tested. The literature has overwhelmingly focused on perceived overqualification. Indeed, of the 61 studies including in Harari and colleagues' (2017) meta-analysis on overqualification, only 5 studies measured objective overqualification. The lack of empirical evidence on the mediating role of perceived overqualification in predicting strain outcomes presents a serious challenge to the conclusions and practical implications that can be drawn from the overqualification literature, as decisions about the appropriateness of hiring an overqualified employee are likely to be based on objective indices of overqualification (Erdogan et al., 2011; Maltarich, Reilly, \& Nyberg, 2011). Indeed, overqualification researchers frequently conflate these two constructs, as an inherent assumption underlying most studies on perceived overqualification is that the findings generalize to objectively overqualified employees.

The goal of the current research is to investigate the relationships between objective overqualification, perceived overqualification, and job satisfaction (Study 1), and shed light on the directionality of the relationship between perceived overqualification and employee job satisfaction (Study 2). As such, this study aims to make several important contributions to the literature. First, it tests the widespread assumption that perceived overqualification mediates the relationships between objective overqualification and strain. Three dimensions of objective overqualification are examined: overeducation, cognitive ability overqualification, and skill overqualification. An analysis of the relationships between three forms of objective 
overqualification, perceived overqualification, and job satisfaction marks an important step forward in determining the utility of P-E fit theory in explaining overqualification and its outcomes. The present research therefore aims to provide much-needed scrutiny to a theoretical framework that is commonly relied upon, but rarely tested, in the literature.

A second contribution of this study is to elucidate the predictors of perceived overqualification. Despite many theorized antecedents, including objective overqualification, personality characteristics (e.g., neuroticism), and organizational politics (Liu \& Wang, 2012), the existing literature provides little empirical evidence on how perceptions of overqualification are actually formed (Erdogan et al., 2011; Feldman, 2011). To our knowledge, the idea that perceptions of overqualification reflects factors other than an objective mismatch between employee qualifications and job demands, such as dissatisfaction with other elements of the job, remains virtually untested. One study (Lee, 2005) found significant negative relationships between perceived overqualification and job autonomy and job variety, but used a crosssectional design, limiting our ability to discern directionality. Understanding the antecedents of perceived overqualification is critical to understanding the best strategy to address its negative consequences. Indeed, if perceived overqualification is shaped by perceptual antecedents such as job satisfaction, the potential implications for hiring managers are vastly different, as screening objectively overqualified applicants will not accomplish what is intended (Erdogan et al., 2011).

A final contribution of this study is to meet the growing call for more methodologically rigorous research. Inappropriate measurement and operationalization of various overqualification dimensions are widespread in the literature, making it difficult to draw conclusions (Maltarich et al., 2011; McKee-Ryan \& Harvey, 2011). Similarly, a preponderance of the overqualification literature has relied on cross-sectional designs, raising concerns about reverse causality (Liu \& 
Wang, 2012). The present research therefore aims to advance the literature by utilizing methodologically rigorous means to support its conclusions. Specifically, in Study 1 we use objective methods to measure objective overqualification rather than direct self-assessments that are commonly used in the overqualification literature (c.f. Luksyte \& Spitzmueller, 2011; Verhaest \& Omey, 2006), and in Study 2 we use a three-wave longitudinal survey of employees to allow stronger inferences regarding the direction of effects (e.g., Hu et al., 2015).

\section{Theoretical Background}

Person-environment (P-E) fit theory posits that compatibility between the characteristics of individuals and their work environments positively influences the way individuals experience those environments (Feldman, 2011; Kristof-Brown, Zimmerman, \& Johnson, 2005). Person-job (P-J) fit is a narrower type of P-E fit that refers to the congruence between an employee's characteristics and the characteristics of the job or tasks performed at work (Kristof-Brown et al., 2005). There are two types of P-J fit: demands-abilities and needs-supplies (Edwards, 1991). Demands-abilities fit refers to the congruence between the demands of a job and employee abilities (e.g., aptitudes, experience, and education) available to meet those demands (Edwards, 1991; Kristof-Brown et al., 2005). Needs-supplies fit involves the congruence between employee needs (e.g., goals, values, and interests), and the job supplies (i.e., job characteristics) available to meet those needs (Edwards, 1991). Overqualification researchers argue that demands-abilities fit is more consistent with the definition of overqualification as a situation in which employee education, experience, knowledge, skills, and abilities exceed job demands (Maynard \& Parfyonova, 2013). Thus, the P-E fit theory approach conceptualizes overqualification as a special type of P-J demands-abilities misfit in which one's qualifications exceed job demands. 
P-E fit theory argues that the objective environment and the objective person have at least some influence on individuals' perceptions, which in turn shape their perceptions of discrepancy and fit between themselves and their environments (Edwards, Cable, Williamson, Lambert, \& Ship, 2006; Kristof-Brown et al., 2005). Overqualification researchers have adopted a similar view, arguing that perceived overqualification at least partially reflects objective overqualification (e.g., Liu \& Wang, 2012). Indeed, some scholars believe the link between the two constructs should be particularly strong, as the mismatch between one's skills and job demands is readily and continually apparent on the job (Feldman, 2011). Objective overqualification aims to ascertain whether objective employee qualifications (i.e., education, experience, knowledge, skills, and abilities) exceed actual job demands and requirements. An example of an objective overqualification measure would involve comparing employees' obtained level of education to the education level required by their jobs. Perceived overqualification, on the other hand, entails an evaluative element in which employees have judged that their qualifications exceed the qualifications required by their jobs. It therefore captures employees' overall perceptions of feeling overqualified (Erdogan et al., 2011).

It is important to distinguish between objective or subjective constructs from objective or subjective measures of overqualification. To illustrate, Verhaest and Omey (2006) identified four ways of measuring objective overeducation. The direct self-report method simply asks employees whether or not they have more education than required by their jobs, and is the most subjective way to measure the objective construct. The indirect self-assessment method asks employees the required education level for their job, and then compares their responses to their actual level of education. The job analysis method bases the required educational level for a given job on job analysis data (e.g., from the Occupational Information Network or O*NET), and 
then compares to the actual level of education. Finally, the realized match method determines the required educational level using the distribution of educational levels for workers in that occupation. Accordingly, the objective overeducation construct can be measured in a number of ways that vary in the extent to which they rely on more subjective versus more objective data.

Very few studies have explicitly tested the relationship between objective and perceived overqualification. Harari and colleagues (2017) analyzed effect sizes in 5 studies and reported a population coefficient of $\rho=.40$. We build upon these studies in two ways. First, we included three indicators of objective overqualification (most studies have looked only at overeducation). Also, whereas some researchers have used dichotomous measures of overqualification (Liu, Luksyte, Zhou, \& Shi, 2015; Maynard, Brondolo, Connelly, \& Sauter, 2015), we incorporated greater precision by using continuous measures, as recommended by Luksyte and Spitzmueller (2011). Although research that employs continuous, multidimensional measures of objective overqualification is needed, preliminary evidence does support the idea that objective and perceived overqualification are related. Accordingly, we present the following hypothesis:

Hypothesis 1: Objective overqualification positively relates to perceived overqualification.

Perceived overqualification as a mediator of objective overqualification and strain outcomes

A central tenet of P-E fit theory is that incongruence between an individual and their environment causes a variety of psychological, physical, and/or behavioral strains, such as dissatisfaction and poorer job performance (Edwards \& Van Harrison, 1993; Kristof-Brown et al., 2005). Further, these strain outcomes are argued to be a direct consequence of perceived, rather than objective, misfit (Edwards, 1996). Objective misfit is posited to have weaker relationships with outcomes since it is a more distal predictor that must be "filtered" through 
employee perceptions, and therefore may reflect elements of the objective environment that are the most salient to a given individual (Kristof-Brown et al., 2005). Similarly, since objective overqualification represents a specific type of objective P-J demands-ability misfit, the P-E fit theory approach entails that its impact on job attitudes and other strain outcomes should be mediated by perceived overqualification (Feldman, 2011; Luksyte \& Spitzmueller, 2011).

To the best of our knowledge, no previous research has explicitly tested perceived overqualification as a mediator of objective overqualification and strain outcomes. However, there is some evidence on their respective relationships with job satisfaction. Harari and colleagues' (2017) meta-analysis found that perceived overqualification negatively relates to job satisfaction. The relationship between objective overqualification and job satisfaction, on the other hand, is less clear. The results appear to depend on the method used to operationalize objective overqualification, with studies that used more objective measures of overqualification generally failing to find significant relationships. Specifically, studies using the job analysis or indirect self-assessment methods did not find significant relationships between objective overqualification and job satisfaction (Friedland \& Price, 2003; Maynard et al., 2015) or need satisfaction (Dumani, 2015) whereas studies using the direct self-assessment method found significant relationships between objective overqualification and job attitudes (McKee-Ryan, Virick, Prussia, Harvey, \& Lilly, 2009; Nabi, 2003). Importantly, however, all but one of these studies (McKee-Ryan et al., 2009) included only one dimension of objective overqualification (e.g., overeducation). It is therefore unclear whether the same pattern would occur with a multidimensional measure of objective overqualification. 
Theories of psychological need fulfillment stipulate that psychological needs such as autonomy and competence are inherent in all humans and are critical for psychological growth and well-being (Ryan, 1995). According to P-E fit theory, employees form perceptions about the extent to which their job supplies certain extrinsic and intrinsic resources and rewards, such as salary and a sense of accomplishment (Cable \& Edwards, 2004). The actual values of these supplies are then cognitively compared to the person's desired values, as shaped by their underlying psychological needs. Dissatisfaction occurs when the actual amount of resources falls short of the desired amounts. Thus, the P-E fit theory approach argues that overqualification results in job dissatisfaction through a lack of psychological need fulfillment (i.e., for autonomy, competence, and relatedness) as well as inadequate levels of extrinsic rewards (e.g., salary) due to the generally lower-level nature of these jobs.

There is ample evidence suggesting that perceived overqualification is associated negatively with the intrinsic resources and extrinsic rewards underlying psychological need fulfillment and satisfaction. For instance, perceived overqualification is associated with a lower salary (Harari et al., 2017), a perceived lack of growth opportunities (Johnson \& Johnson, 1999), cynicism about the meaningfulness of one's job (Luksyte, Spitzmueller, \& Maynard, 2011), and a perceived lack of job autonomy and variety (Lee, 2005). Similarly, Dumani (2015) found that perceived overqualification negatively relates to fulfillment of the needs for autonomy and relatedness. These findings support the idea that perceived overqualification results in job dissatisfaction because employees feel that such job situations are characterized by inadequate levels of internal and external resources and rewards.

In sum, P-E fit theory argues that job situations in which employees feel overqualified are evaluated as undesirable and inadequate. The P-E fit theory approach emphasizes how 
psychological need fulfillment and extrinsic motivation processes influence the cognitive evaluation of this discrepancy, and stipulates that perceived overqualification mediates the relationship between objective overqualification and job dissatisfaction. Accordingly, we present the following hypotheses:

Hypothesis 2. Objective overqualification negatively relates to job satisfaction. Hypothesis 3. Perceived overqualification negatively relates to job satisfaction. Hypothesis 4. Perceived overqualification mediates the relationship between objective overqualification and job satisfaction.

\section{Study 1}

The purpose of Study 1 was to examine the relationship between objective overqualification and perceived overqualification (Hypothesis 1) and their respective relationships with job satisfaction (Hypotheses 2-3). Study 1 also aimed to test the theoretical model in which perceived overqualification mediates the relationship between objective overqualification and job satisfaction (Hypothesis 4).

\section{Method}

\section{Participants and procedure}

The sample consisted of 162 full-time employed (30 or more hours per week) recent college graduates with a bachelor's degree in psychology from a large public university located in the southeastern United States. Participants were recruited in two ways. First, recent graduates were recruited using an alumni contact list and invited to participate in the study via physical mail. Second, seniors majoring in psychology were recruited via a mass email explaining the research teams' interest in learning about their post-graduation career experiences. Interested students provided their contact information and expected graduation date, and were contacted 
approximately six months following graduation. Participants received a letter or email inviting them to participate in the study and contained a link to the online survey. Responses to the survey were anonymous, and participants received a $\$ 5.00$ gift card as compensation. A total of 174 completed survey responses were received. After screening cases where participants did not meet eligibility criteria or demonstrated evidence of random responding (i.e., failing to correctly answer two or more instructed response items), the final sample included 162 participants.

The average age of participants was 24.3 years $(\mathrm{SD}=2.2)$. The sample was mostly female (85\%) and Caucasian (69\%). The average length of time between participants' graduation date and the date of study completion was 18.1 months $(\mathrm{SD}=8.4)$. Participants were employed in a diverse range of occupations, reporting job titles such as "clinical case manager," "deputy sheriff," and "animal care technician." Participants had an average job tenure of 13.4 months $(\mathrm{SD}=12.4)$ and worked an average of 38.7 hours per week $(\mathrm{SD}=5)$. Nearly a quarter of participants $(23.5 \%)$ indicated that they had received formal post-baccalaureate education. Classification into $O * N E T-S O C$ occupations

Participants were classified by the first author into an occupation based on their selfreported job titles and job industries, and on the Occupational Information Network's (O*NET) Standard Occupational Classification (SOC) taxonomy. O*NET is a comprehensive database of job characteristics and worker attributes that is sponsored by the U.S. Department of Labor. O*NET-SOC occupations were assigned to 158 out of 162 participants. Participants' O*NETSOC occupations were used to obtain objective ratings of job-level cognitive demands, skill demands, and education requirements, which are described in greater detail below. Although O*NET data cannot provide context-specific information on a given individual's job, $\mathrm{O} * \mathrm{NET}$ ratings of job characteristics have been found to converge with individual-level incumbents' 
ratings (Liu, Spector, \& Jex, 2005) and are frequently used in studies examining individual-level phenomena (e.g., Fisher et al., 2014; Maltarich et al., 2011).

\section{Measures}

Objective overqualificationObjective overqualification was measured using three indicators: overeducation, skill overqualification, and cognitive ability overqualification. This operationalization is consistent with the definition of overqualification as a situation in which employees possess more education, experience, and KSAs (i.e., knowledge, skills, and abilities) than required by their jobs (Erdogan et al., 2011). We used the job analysis method to operationalize overeducation and cognitive ability overqualification, and a combination of job analysis and indirect self-assessment to measure skill overqualification (Verhaest \& Omey, 2006). The three indicators were combined into one objective overqualification measure for direct tests of the hypotheses and testing of our measurement model.

Overeducation. Overeducation was measured by calculating the difference between individuals' years of education to the typical years of education required by their current jobs, as rated by O*NET or the U.S. Bureau of Labor Statistics (BLS). Specifically, O*NET provides the highest level of education obtained by a majority of incumbents for a given occupation. BLS ratings from the Occupational Outlook Handbook were used for 17 occupations missing O*NET data on required education level. The years of education associated with each education level were determined using definitions provided by the U.S. Bureau of Labor Statistics (2016) and the coding procedure followed by Friedland and Price (2003). ${ }^{1}$ This method treats overeducation as a continuous, rather than dichotomous, variable (e.g., Luksyte \& Spitzmueller, 2011).

\footnotetext{
${ }^{1}$ Occupations requiring a doctoral or professional degree were coded as requiring 19 years of education, occupations requiring a master's degree were coded as requiring 17.5 years, occupations requiring a bachelor's degree were coded as requiring 16 years, occupations requiring an associate's degree were coded as requiring 14 years, occupations requiring some postsecondary education but no degree were coded as requiring 13 years, occupations
} 
The years of education completed by participants were determined using the same categories as above. Since all participants had completed their bachelor's degree, the minimum years of education among participants was 16 .

In order to check the construct validity of our overeducation variable, we compared the required education level (in years) for the occupation reported by $\mathrm{O} * \mathrm{NET}$ or the BLS $(\mathrm{M}=14.15$, $\mathrm{SD}=2.25$ ) with participants' self-reports of the required education level (in years) for their jobs $(\mathrm{M}=14.19, \mathrm{SD}=2.01)$. There was a significant correlation between the two, $r=.53, p<.01$, confirming that the occupation-level data converged with job-level data.

Skill overqualification. Skill overqualification was operationalized as the difference between the sum of individuals' ratings of their competence in 35 skills and the sum of O*NET ratings of the importance of those 35 skills to their occupations. ${ }^{2} \mathrm{O} * \mathrm{NET}$ provides a rating of the importance of each skill to a given occupation on a scale from 1 (not important) to 5 (extremely important). Participants were presented with a description of each O*NET skill and asked to rate their competency in each skill on a scale ranging from 1 (This is not a skill of mine) to 5 (I am excellent at this skill). Thus, skill overqualification was measured using unstandardized (raw) O*NET and self-report scores.

Cognitive ability overqualification. Cognitive ability overqualification was measured as the difference between participants' standardized SAT scores and standardized O*NET ratings of the cognitive demands of their jobs. SAT (critical math and reading) scores and American College Test (ACT) scores converted into SAT scores were used to measure participants' cognitive ability. Both the SAT and ACT have been found to correlate highly with established

requiring a high school diploma were coded as requiring 12 years, and occupations requiring less than a high school diploma were coded as requiring 10 years.

${ }^{2}$ O*NET skills include 10 basic skills (e.g., writing), one complex problem solving skill, four resource management skills (e.g., time management), six social skills (e.g., persuasion), three systems skills (e.g., judgment and decision making), and 11 technical skills (e.g., troubleshooting). 
measures of cognitive ability, indicating that both are acceptable measures of general intelligence (Frey \& Detterman, 2004; Koenig, Frey, \& Detterman, 2008).

One-hundred and sixteen (116) out of 162 participants (72\%) reported an SAT or ACT score. Participants who reported composite ACT scores were assigned SAT (total math and critical reading) scores using concordance tables provided by College Board, the publisher of the SAT. Participants' SAT scores were then standardized using the mean and standard deviation for all SAT test takers in their class cohort, based on the year they graduated from high school. Descriptive statistics came from annual data released by College Board for all high school seniors who took the SAT at any point during their high school years. Participants' standardized SAT therefore represents their cognitive ability relative to the general population of high school students who take the SAT or ACT. There is evidence the population of SAT- and ACT-takers increasingly approximates the general population (Adams, 2014; Teicher Khadaroo, 2015).

Cognitive demands of the job were calculated by averaging $\mathrm{O} *$ NET ratings of the importance of 21 cognitive abilities to an occupation (see Maltarich, Nyberg, \& Reilly, 2010, for a similar approach). O*NET cognitive abilities include elements such as inductive reasoning, number facility, and written comprehension, and are rated on a scale from 1 (not important) to 5 (extremely important). Average cognitive demands for participants' occupations were standardized using the mean and standard deviation of the average cognitive demands of all occupations available in $\mathrm{O} * \mathrm{NET}$. A positive score on cognitive ability overqualification thus indicates that an individual's cognitive ability (relative to the general population of highschoolers who take the test) is greater than the cognitive demands of the job (relative to the cognitive demands of all occupations). A negative score indicates that an individual's standing on cognitive ability is lower than his or her job's standing in cognitive demands. 


\section{Perceived overqualification}

Perceived overqualification was measured using the nine-item Scale of Perceived

Overqualification (SPOQ; Maynard et al., 2006). A sample item is "I have more abilities than I need in order to do my job." Response options ranged from 1 (strongly disagree) to 5 (strongly agree). The scale demonstrated high reliability $(\alpha=.91)$.

\section{Job satisfaction}

Job satisfaction was measured with the three-item subscale from the Michigan Organizational Assessment Questionnaire (MOAQ; Cammann, Fichman, Jenkins, \& Klesh, 1983). A sample item is “All in all, I am satisfied with my job.” Response options ranged from (strongly disagree) to 5 (strongly agree). The scale demonstrated high reliability $(\alpha=.91)$.

\section{Demographics}

Participants were asked to report their age, gender, ethnicity, and their dates of graduation from high school and college. Participants were also asked to report their job title, NAICS job industry, job tenure, average work hours per week, the required education level of their jobs, and whether they had completed any formal education after graduating from college.

\section{Results}

\section{Confirmatory factor analyses}

In order to assess the extent to which the measures fit their hypothesized latent constructs, we performed a three-factor confirmatory factor analysis (CFA) on objective overqualification (unstandardized estimates of the three indicators), perceived overqualification (nine-item scale), and job satisfaction (three-item scale). The analyses were conducted in Mplus Version 7.0 (Muthén \& Muthén, 1998-2012) using robust full-information maximum likelihood estimation (MLR). The measurement model demonstrated poor fit to the data, $\left(\chi^{2}(87)=242.02\right.$, 
$p<.001, \mathrm{CFI}=.87, \mathrm{TLI}=.84, \mathrm{RMSEA}=.11 ; \mathrm{Hu} \&$ Bentler, 1999). An examination of residual variance and covariances and factor loadings indicated that the perceived overqualification scale (SPOQ) was a potential source of misspecification.

Maynard and colleagues (2006) encountered similar issues regarding the scale's factor structure. Specifically, although the results of principal components analyses (PCAs) indicated that one factor explained most of the variance in the nine items, a three-factor CFA model fit the data better than a one-factor model. The authors still maintained that the high internal consistency of the scale and the results of the PCAs warranted its use as a unidimensional measure. However, three dimensions clearly emerge from the SPOQ: three items assess excess education, three assess excess KSAs, and three assess excess experience and training. It is therefore possible that a higher-order model with three first-order factors best fits the SPOQ.

Since the SPOQ is used as a unidimensional scale in the literature, and establishing its appropriate factor structure is beyond the scope of the present study, we chose to address this issue by creating three-item parcels for each dimension of the SPOQ: overeducation, excess KSAs, and overexperience. The score for each parcel was calculated by taking the average score of the three items assigned to it. This strategy is referred to as domain-representative or facetrepresentative parceling (Little, Cunningham, Shahar \& Widaman, 2002; Little, Rhemtulla, Gibson, \& Schoemannand, 2013). The facet-representative strategy has been argued to be a justifiable means of addressing multidimensionality using parceling techniques, particularly when lower-order dimensions of a factor are not of theoretical interest (Little et al., 2013). Furthermore, given that these parcels generally behave like a facet, there is evidence that they result in the least biased parameter estimates, and models that employ them have been found to remain sensitive to misspecification (Little et al., 2013). 
Fit was acceptable for the three-factor CFA in which domain-representative parcels were used as indicators of perceived overqualification $\left(\chi^{2}(24)=49.53, p<.01, \mathrm{CFI}=.96\right.$, TLI $=.94$, RMSEA = .08). Factor loadings ranged from .50-.93.

\section{Descriptive statistics and correlational analyses}

Descriptive statistics, reliabilities, and intercorrelations among variables are presented in Table 1. A composite objective overqualification variable was created by standardizing and summing scores on skill overqualification, overeducation, and cognitive overqualification.

Hypothesis 1, which stated that objective overqualification would positively relate to perceived overqualification, was supported for overall objective overqualification $(r=.54, p<$ $.01)$ as well as its three facets ( $r$ 's ranged From .32 to $.54, p<.01)$. Job satisfaction did not significantly relate to objective overqualification $(r=-.11, n s)$ or any of its facets ( $r$ 's ranged from -.14 to $.04, n s$ ), thus failing to support Hypothesis 2. Finally, perceived overqualification negatively related to job satisfaction $(r=-.38, p<.01)$. Hypothesis 3 was therefore supported.

\section{Structural equation modeling}

To test Hypothesis 4, we estimated a structural model in which composite objective overqualification predicted perceived overqualification, which in turn predicted job satisfaction. The three (unstandardized) indicators of overeducation, skill overqualification, and cognitive ability overqualification were used as indicators of objective overqualification, the three facetrepresentative parcels of the SPOQ were used as indicators of perceived overqualification, and the three items of the job satisfaction scale were specified as indicators of job satisfaction. The model fit the data well, $\chi^{2}(25)=50.58, p<.01, \mathrm{CFI}=.97, \mathrm{TLI}=.95, \mathrm{RMSEA}=.08$. The path coefficients corroborated the results of the correlation analyses, with objective overqualification 
positively predicting perceived overqualification $(\gamma=.60, p<.001$; Hypothesis 1$)$ and perceived overqualification negatively predicting job satisfaction $(\gamma=-.41, p<.001$; Hypothesis 3$)$.

We used a bootstrap estimation approach with 10,000 samples to test the significance of the indirect effect (Cheung \& Lau, 2008). There was a negative and significant indirect effect of objective overqualification on job satisfaction through perceived overqualification $(b=-.26, \mathrm{SE}$ $=.06, p<.001,95 \% \mathrm{CI}=-.16,-.40)$. The results therefore supported the mediation effect stipulated in Hypothesis 4. Figure 1 contains the SEM results of the hypothesized model. ${ }^{3}$

\section{Discussion}

Study 1 sought to propose and test a model of objective overqualification, perceived overqualification, and job satisfaction based on P-E fit theory, a commonly-used framework for understanding the outcomes of overqualification. A key goal of this investigation was to examine the extent to which employees' perceptions of being overqualified are grounded in objective indicators of overqualification, which has long remained a critical open question in the literature. Consistent with our expectations, and among overqualification researchers more generally, objective overqualification and perceived overqualification were positively related. Employees' perceptions of being overqualified therefore do appear to have some basis in reality, as predicted by P-E fit theory. At the same time, however, the effect size found in the present study $(r=.54)$ implies that these two constructs each possess a substantial degree of unique variance.

The distinctiveness of these two constructs is further evinced by the unique patterns of relationships they demonstrated with job satisfaction. Specifically, only perceived

\footnotetext{
${ }^{3}$ In addition to the analysis described here, we ran three additional models: one for each of the three objective overqualification indicators (instead of the overall objective overqualification factor). The three models fit the data well, and retained the same pattern of results. In addition, the pattern of results did not change when adding the direct path from objective overqualification to job satisfaction (this path estimate was not significant), nor did the results change upon adding the following control variables: gender, age, hours of work, ethnicity, and organizational tenure. These analyses can be obtained from the first author.
} 
overqualification negatively related to job satisfaction $(r=-.38)$, and this correlation was significantly larger (dependent t-test; Williams, 1959) than the corresponding objective overqualification correlation $(t(108)=3.17, p<.05)$. These findings are consistent with a study by Spector and Jex (1991), which compared ratings of job characteristics from incumbents, independent raters, and the Dictionary of Occupational Titles (DOT) and found that only incumbent ratings predicted incumbents' job satisfaction and turnover intentions. The nonsignificant correlation between objective overqualification and job satisfaction also corroborates the results of previous studies that failed to find a significant relationship between these two variables (e.g., Friedland \& Price, 2003; Maynard et al., 2015), and expands the generalizability of this pattern using a multifaceted measure of objective overqualification.

Another goal of Study 1 was to clarify the respective roles of objective and perceived overqualification in predicting job dissatisfaction. The results of SEM were consistent with the proposed model, which holds that objective overqualification predicts job dissatisfaction through perceived overqualification. It should be kept in mind, however, that inferences about indirect effects cannot be drawn from cross-sectional designs. Further, it is possible that the effects of perceived overqualification on job satisfaction are reversed. Specifically, the findings that perceived overqualification negatively relates to job satisfaction, but objective overqualification does not, raises the possibility that the pathways specified in our mediation model are incorrect.

One possibility is that dissatisfied employees perceive an exaggerated discrepancy between their qualifications and the demands of their jobs. To the best of our knowledge, this idea has never been tested. However, several researchers have raised the possibility of reverse causality between perceived overqualification and job attitudes (Erdogan et al., 2011) and job characteristics (Hu et al., 2015). This idea has received support from the broader job attitudes 
literature. For example, James and Jones (1980) found that job satisfaction was a stronger predictor of perceived job characteristics (job complexity and autonomy) than the reverse. Similarly, Houkes, Janseen, de Jonge, and Bakker (2003) found that turnover intentions predicted unmet expectations regarding the job's opportunities for growth and development, responsibility, and salary, but not the reverse. Empirical findings support the notion that job attitudes can shape perceptions of job characteristics, which raises the possibility that job satisfaction may predict perceived overqualification. We investigated this possibility in Study 2 .

\section{Study 2}

The purpose of Study 2 was to investigate directionality between perceived overqualification and job dissatisfaction using a multiwave panel study design. Our Study 1 results led us to consider an alternative pattern that might underlie the robust perceived overqualification-job satisfaction relationship found in the literature: reverse causality. We therefore draw upon findings from the job attitudes literature to propose that dissatisfaction with the job predicts perceived overqualification. Employees who are dissatisfied with elements of their job for reasons apart from their excess qualifications (e.g., a lack of interest in the work) may experience heightened perceptions of overqualification. It may be that job dissatisfaction sensitizes employees to objective overqualification when it actually exists, such that dissatisfied employees are more likely to realize that their talents and skills are underutilized on the job, or that it biases employee judgment, such that dissatisfied employees believe themselves to be more overqualified than they objectively are. Similarly, employees who are satisfied with their jobs may be less likely to notice objective overqualification, and may experience heightened judgments that their qualifications are well-suited to their job demands. Consistent with P-E fit theory, and the broader overqualification literature, we also propose the traditional directions of 
effects: that perceived overqualification predicts subsequent job dissatisfaction. Although our Study 1 results is that the direction of effects do not flow from objective overqualification to job satisfaction, the P-E fit theory-based hypothesis regarding the predictive influence of perceived overqualification on subsequent job satisfaction requires an explicit test using a longitudinal design. Accordingly, we present competing hypotheses:

Hypothesis 5. Perceived overqualification negatively predicts subsequent job satisfaction. Hypothesis 6. Job satisfaction negatively predicts subsequent perceived overqualification. Another goal of Study 2 was to examine the generalizability of our Study 1 findings. Study 1 used a sample of recent psychology graduates. On the one hand, recent college graduates may be especially vulnerable to experiencing perceived overqualification and its correlates, since they are new entrants to the job market (Erdogan \& Bauer, 2009). On the other hand, psychology majors may not have high expectations for their new jobs, since their degrees are less specialized than others. As a result, they may not feel as dissatisfied in jobs that they believe they are overqualified for. Thus, another goal of Study 2 was to investigate whether the pattern observed between perceived overqualification and job satisfaction in Study 1 held in a different sample.

It should be noted that we did not include a measure of objective overqualification in Study 2, as it was unlikely that participants would experience significant changes in their job title or qualifications over the relatively short time frame. Therefore, the objective overqualification level should be fairly constant for each individual, leaving little to be gained from examining the directionality between objective overqualification and perceived overqualification or job satisfaction.

\section{Method}

Participants and procedure 
Participants were 558 full-time staff employees at a large public university in the southeastern United States. Participants were mostly female (70\%) and Caucasian (66\%). They had an average age of 42.6 years $(S D=13.0)$ and worked an average of 42.4 hours per week $(S D$ =6.4). Of these 558 participants, 230 participated at Time 2, and 155 participated at Time 3 . A series of independent samples t-tests found no significant differences between individuals who dropped out before Time 3 (i.e., those individuals who only completed Time 1, or who only completed Times 1 and 2) and individuals who remained through Time 3 (i.e., those individuals who completed all three time points) on any focal study variables.

This study was part of a larger study on perceived overqualification. Participants were recruited using publicly available email addresses. They first received an email invitation to participate in an anonymous online survey about their work experiences and attitudes. At the end of the first survey, participants were directed to a second, separate survey in which they provided an e-mail address if they were willing to continue in the study. Each of the three surveys were approximately 1.5 weeks apart, for a total study duration of 4 weeks. Participants were matched across the three time points using three unique identifiers. They were entered into a drawing for a \$25 gift card for their time, with separate drawings for each of the three surveys.

\section{Measures}

\section{Perceived overqualification}

Perceived overqualification was measured with the nine-item SPOQ (Maynard et al., 2006). The scale demonstrated high reliability across all three time points, with internal consistency reliability coefficients $(\alpha)$ ranging from .92 to .94 .

\section{Job satisfaction}


Job satisfaction was measured with the three-item subscale from the MOAQ (Cammann, et al. 1983). The scale demonstrated adequate reliability across all three time points, with $\alpha$ coefficients ranging from .82 to .86 .

\section{Results}

Descriptive statistics, reliabilities, and intercorrelations of the study variables are presented in Table 2. The correlations indicated that perceived overqualification and job satisfaction were negatively correlated, both within each time point and across all three time points. For the confirmatory factor analyses and structural equation model, we addressed multidimensionality in the SPOQ using the same techniques discussed in Study 1, and created three facet-representative parcels as indicators of perceived overqualification.

\section{Confirmatory factor analyses}

As a first step, we conducted a set of confirmatory factor analyses using MLR estimation in Mplus Version 7.0 (Muthén \& Muthén, 1998-2012). We first ran a model in which each indicator loaded onto its respective factor in each of the three time points, with a total of six correlated factors (one factor per construct and measurement occasion). This model demonstrated good fit $\left(\chi^{2}(102)=224.83, p<.001, \mathrm{CFI}=.97, \mathrm{TLI}=.95, \mathrm{RMSEA}=.05\right)$.

Next, we tested for measurement invariance of the latent variables across time. We compared our six-factor model with a model that was identical except for the fact that it constrained the factor loadings of each indicator to be equal across the three time points. The constrained model had good fit $\left(\chi^{2}(110)=243.99, p<.001\right.$, CFI $=.96$, TLI $=.95$, RMSEA $\left.=.05\right)$. A test of these nested models using the Satorra-Bentler $\chi^{2}$ scaled difference test (Satorra \& Bentler, 2001) indicated that the constrained model fit the data significantly worse than the unconstrained model, $\left(\Delta \mathrm{SB}-\chi^{2}(8)=19.29, p<.05\right)$. However, researchers have cautioned against 
using the chi-square difference test for measurement invariance testing, as its sensitivity to sample size and nonnormality can result in model rejection even when there are only trivial discrepancies between two models (Chen, 2007). As such, we relied on two of Chen's (2007) recommended benchmarks for testing measurement invariance: $\Delta \mathrm{CFI}<.01$ and $\Delta \mathrm{RMSEA}<$ .015. Differences between constrained and unconstrained models were within accepted criteria $(\triangle \mathrm{CFI}=.004$ and $\triangle \mathrm{RMSEA}=.001)$, supporting measurement invariance. We therefore retained the constrained model. Factor loadings ranged from .70 to .95 .

\section{Structural equation modeling}

In order to test Hypotheses 5 and 6, we tested a cross-lagged panel model. In crosslagged panel models, an endogenous latent variable is regressed onto its own lagged score (autoregression) and the lagged score of another variable (cross-lagging; Berrington, Smith, \& Sturgis, 2006). The autoregressive coefficients represent the stability of individuals' scores on perceived overqualification and job satisfaction over time. The cross-lagged coefficients demonstrate whether individual standing on perceived overqualification (job satisfaction) at Time $\mathrm{x}$ predicts individual standing on job satisfaction (perceived overqualification) at Time ${ }_{\mathrm{X}+1}$ after controlling for standing on job satisfaction (perceived overqualification) at Time ${ }_{\mathrm{x}}(\mathrm{Wu}$, Selig, \& Little, 2013). We allowed the disturbances of the indicators to correlate across time points (Cole \& Maxwell, 2003), and constrained the structural coefficients to be equal across time points. The model demonstrated good fit to the data $\left(\chi^{2}(118)=255.42, p<.001, \mathrm{CFI}=.96\right.$, $\mathrm{TLI}=.95, \mathrm{RMSEA}=.05)$. We compared this constrained structural model to an unconstrained model in which the path coefficients were free to vary across time points. The unconstrained model did not fit significantly better than the constrained model based on both Chen's (2007) 
recommended benchmarks $(\Delta \mathrm{CFI}=-.001$ and $\triangle \mathrm{RMSEA}=-.001)$ and the stricter Satorra-Bentler $\chi^{2}$ scaled difference test $\left(\Delta \mathrm{SB}-\chi^{2}(4)=2.92, n s\right)$. We therefore retained the constrained model.

Contrary to Hypothesis 5, the relationship between perceived overqualification and subsequent job satisfaction was not significant. Specifically, neither the Time 1 perceived overqualification to Time 2 job satisfaction path nor the Time 2 perceived overqualification to Time 3 job satisfaction path was significant (for both paths, $\gamma=.02, n s$ ). However, there was a significant relationship between job satisfaction and subsequent perceived overqualification. The Time 1 job satisfaction to Time 2 perceived overqualification path and the Time 2 job satisfaction to Time 3 perceived overqualification path were both significant (for both paths, $\gamma=$ $-.05, p<.05)$. Hypothesis 6 was therefore supported. Path estimates are shown in Figure 2.

Finally, we investigated whether the effect size between perceived overqualification and job satisfaction differed across studies by conducting two t-tests for independent samples. No significant differences were found between the Study 1 correlation and the cross-sectional correlations in Study 2 (for the T1 comparison, $z=0.94, p=.35$; for $\mathrm{T} 2, z=.5, p=.62$ ).

\section{Discussion}

Study 2 investigated directionality between perceived overqualification and job satisfaction. The pattern of results found in Study 1 led us to consider the possibility of reverse causality, which has been observed in previous longitudinal studies on job characteristics and job attitudes. We therefore proposed that job satisfaction might predict subsequent perceived overqualification. However, we also explicitly tested the traditional hypothesis that perceived overqualification would predict subsequent job satisfaction, as stipulated by P-E fit theory and the broader overqualification literature. We obtained evidence that job dissatisfaction appears to predict perceived overqualification and not the reverse. 
Although we did not measure objective overqualification in Study 2, our results support and extend Study 1's correlational findings by suggesting that there may not be a predictive effect from objective overqualification to job dissatisfaction. Specifically, if objectively overqualified employees did indeed perceive their own overqualification and experience poorer job satisfaction as a result, we would have expected to observe a significant predictive relationship between perceived overqualification and subsequent job dissatisfaction. However, that was not the case in our study. Our present findings therefore lead us to suggest that the portion of objective overqualification that relates to perceived overqualification may be largely distinct from the portion of perceived overqualification that relates to job satisfaction. Finally, given that we found no significant differences in the perceived overqualification-job satisfaction relationship across studies, Study 2 supports the generalizability of our findings in Study 1.

\section{General Discussion}

The goal of the present study was to investigate the nature of the relationships between objective overqualification, perceived overqualification, and job satisfaction. In Study 1, we tested the mediation model delineated by P-E fit theory and other common frameworks in the overqualification literature. Although our proposed model demonstrated good fit to the data, we were cautious of interpreting indirect effects in a cross-sectional model, and the nonsignificant relationship between objective overqualification and job satisfaction led us to speculate that there may be reversed influences on perceived overqualification. We tested this possibility in Study 2 by examining directionality between perceived overqualification and job satisfaction using three measurement waves over the course of one month. Contrary to P-E fit theory, we only detected a predictive influence of job dissatisfaction on subsequent perceived overqualification. Overall, the results of both studies suggest that overqualification researchers must take seriously the 
possibility that perceived overqualification is an outcome of both objective demands-abilities misfit (i.e., objective overqualification) and job dissatisfaction.

On the whole, our findings across two studies contradict the nearly unanimous view in the literature that perceived overqualification mediates the relationships between objective overqualification and strain outcomes such as poor job attitudes, as stipulated by P-E fit theory, relative deprivation theory (Crosby, 1976), and other comprehensive models of overqualification (e.g., Liu \& Wang, 2012). Our results therefore highlight the fact that the processes through which objective and perceived overqualification affect, and are affected by, important employee outcomes remain poorly understood. From a practical perspective, our results support the simple yet critical observation that simply screening objectively overqualified applicants may not solve the problems associated with perceived overqualification (Erodogan et al., 2011).

\section{Theoretical implications}

Our results have important implications for the overqualification literature. First, our findings call for new paradigms that can better explain how perceptions of overqualification are formed, and provide a more nuanced account of how perceived overqualification relates to various strain outcomes. For instance, perceived overqualification may predict some behavioral strains (e.g., CWB; Liu et al., 2015), but may be an outcome of other strains (e.g., job dissatisfaction, burnout). Second, our findings strongly encourage overqualification scholars to challenge common assumptions and practices in their research. For instance, implicit in the discussions of many, if not most, published studies on overqualification is the idea that findings on perceived overqualification apply to objectively overqualified employees. However, the results in the present study suggest that this is not the case. Researchers should therefore take care to emphasize the distinction between perceptions and the reality of overqualification. 
Another important theoretical implication pertains to our understanding of objective overqualification. Of the objective overqualification facets included in Study 1, overeducation had the strongest relationships with the overall composite measure of objective overqualification and perceived overqualification. ${ }^{4}$ This suggests that overeducation is perhaps the most critical aspect of objective overqualification, at least among the facets examined this study. Thus, overqualification scholars should be aware that an objective discrepancy between one's actual and required education level may be particularly noticeable and impactful for employees.

\section{Practical implications}

The overqualification literature has largely focused on perceived overqualification, even though hiring decisions are often made on the basis of objective overqualification (Maltarich et al., 2011). However, the present study indicates that using findings on perceived overqualification to draw conclusions about how objectively overqualified applicants and employees might experience and behave on the job may be misleading, if not overtly harmful (Maltarich et al., 2011). Practitioners and hiring managers should be aware that perceptions of overqualification may be a symptom, rather than a cause, of employee dissatisfaction, and should not assume that objectively overqualified individuals are undesirable applicants or employees.

\section{Limitations and future directions}

Our study is not without limitations. First, we did not measure all dimensions of objective overqualification in Study 1. Although assessing three separate dimensions marks important progress in the operationalization of the objective overqualification construct, future research should also incorporate objective overexperience and excess knowledge. Second, given our use of $\mathrm{O}^{*}$ NET data, we measured objective overqualification at the occupation level, not the job level. Although we confirmed that at least one of our objective overqualification dimensions

\footnotetext{
${ }^{4}$ We performed several dependent-sample t-tests to confirm this. Results can be obtained from the first author.
} 
corresponded to participants' self-reports, our objective overqualification measure may not have fully captured job-level information. One possible avenue for gaining job-level data is through supervisor reports or human resources personnel (e.g., Liu et al., 2015). Similarly, due to our use of $\mathrm{O}^{*}$ NET data, our measures of objective cognitive ability and skill overqualification in Study 1 combined variables on slightly different metrics (i.e., importance versus level possessed). Future research could address this issue by obtaining required and possessed levels of skills and abilities directly from supervisors and participants. Next, there was a significant degree of participation attrition in Study 2. Although we did not detect significant differences in our focal study variables between individuals who participated at all three time points and those who did not, it is still possible that non-random participant attrition may have influenced our results.

A fourth limitation is the particular time lag used in Study 2. We selected our time lags of 1.5 weeks, and our total study time frame of one month, based on our expectations that these time periods would be adequate to allow for job-related input (e.g., shifts in work tasks, affective work events) that can shape perceptions of overqualification and job satisfaction. At the same time, however, we recognize the importance of replicating our findings with varying time lags. Studies over longer time frames would also help elucidate the stability of perceived overqualification, which remains largely unknown, given the limited number of longitudinal studies. Study 2 does provide some insight into this question by indicating that perceived overqualification is relatively stable over the course of one month. Despite its high stability, the fact that perceived overqualification was more stable than job satisfaction lends confidence to our results. Directional effects from job satisfaction to perceived overqualification were statistically harder to detect; yet we still detected them, and did not detect the reverse. 
Another limitation of our study is that we did not include objective overqualification in Study 2. Since the aim of Study 2 was to investigate directionality between perceived overqualification and job satisfaction, and capturing significant variance in job titles or participant qualifications could take a matter of years, we did not include a measure of objective overqualification. Studies with longer time frames should investigate the relationship between objective overqualification and dissatisfaction both within and across jobs using other potential mediators (e.g., needs-supplies fit) and moderators (e.g., whether the overqualification is voluntary or involuntary). Such studies could also provide insight into whether job satisfaction and perceived overqualification lead to self-selection into jobs with different levels of objective overqualification. Finally, although our study indicates that job satisfaction is as an antecedent of perceived overqualification, the present study precludes causal inferences. To obtain support for causal claims, future research should investigate potential mediators between dissatisfaction and perceived overqualification using longitudinal designs (e.g., job-related boredom; Liu \& Wang, 2012). Researchers should also consider using experimental designs to enhance internal validity. In general, our study suggests that it is critical for overqualification researchers to investigate the type of work events and conditions that serve as antecedents of perceived overqualification. Although our results indicate that job dissatisfaction is one such predictor, the path coefficients were relatively small and underscore the need to explore other potential antecedents of perceived overqualification as well. For instance, even if an individual possesses an education and experience level required by their jobs, they may be assigned tasks that they find uninteresting, which may heighten their overqualification perceptions. Preliminary support for this idea was found in a cross-sectional study by Luksyte and colleagues (2011), who reported that perceived overqualification related to needs-supplies misfit but not demands- 
abilities misfit. Finally, given its distinctiveness from perceived overqualification, conceptual and empirical work is needed to better understand how objective overqualification influences employee outcomes. For example, objectively overqualified employees might receive beneficial effects from the social and psychological rewards associated with superior job performance.

This brings us to a final note about our study. Employees may deliberately choose jobs for which they are overqualified in order to have a less demanding schedule or accommodate nonwork responsibilities, or because the job deeply aligns with their values (Erdogan et al., 2011). The extent to which overqualifiction is voluntary or involuntary likely plays an important role in shaping employee perceptions and outcomes of overqualification. First, it may moderate the relationship between objective overqualification and perceived overqualification, such that voluntarily overqualified employees are less likely to perceive that they are overqualified when they objectively are. Second, it may moderate the relationship between perceived overqualification and job satisfaction, such that voluntarily overqualified are less dissatisfied with their jobs even if they perceive themselves as overqualified. Although these questions are beyond the scope of the present study, this is an important area for future research. It could also provide insight into the question of whether there are certain situations in which employers should be especially willing to hire objectively overqualified workers.

\section{Concluding remarks}

Given factors such as the growing "gig economy" (Donovan, Bradley, \& Shimabukuro, 2016) and the ever-increasing rate of new workforce entrants with college degrees, it is likely that overqualification will remain an issue for individuals and employers in the years to come. A relatively new body of research on overqualification has produced valuable insight on the correlates of perceived overqualification, and its potential boundary conditions. However, our 
present findings suggest that future research should challenge certain theories and assumptions that are commonly relied upon in the overqualification literature, and seek new theoretical and conceptual paradigms. Our results also call for caution against the conclusion that being objectively overqualified is necessarily an undesirable circumstance for individuals and employers. We encourage future research in this area to focus more on the predictors, as opposed to the outcomes, of perceived overqualification, so that scholars and practitioners alike can gain a greater understanding of the circumstances that create these perceptions, and make appropriate recommendations to managers regarding the hiring of objectively overqualified employees. 


\section{References}

Adams, C.J. (2014). State initiatives widen reach of ACT, SAT tests. Education Week, 34, 1, 10-11.

Berrington, A., Smith, P. W. F., \& Sturgis, P. (2006). An overview of methods for the analysis of panel data (ESRC National Centre for Research Methods Briefing Paper No. 7). Southampton: University of Southampton

Cable, D. M., \& Edwards, J. R. (2004). Complementary and supplementary fit: A theoretical and empirical integration. Journal of Applied Psychology, 89, 822-834. http://dx.doi.org/10. $1037 / 0021-9010.89 .5 .822$

Cammann, C., Fichman, M., Jenkins, G. D., \& Klesh, J. (1983). Michigan Organizational Assessment Questionnaire. In S.E. Seashore, E.E. Lawler, P.H. Mirvis, \& C. Cammann (Eds.), Assessing organizational change: A guide to methods, measures, and practices (pp. 71-138). New York; Wiley-Interscience.

Chen, F. F. (2007). Sensitivity of goodness of fit indexes to lack of measurement invariance. Structural Equation Modeling, 14, 464-504.http://dx.doi.org/10.1080/10705510701 301834

Cheung, G. W., \& Lau, R. S. (2008). Testing mediation and suppression effects of latent variables: Bootstrapping with structural equation models. Organizational Research Methods, 11, 296-325. http://dx.doi.org/10.1177/1094428107300343

Cole, D. A., \& Maxwell, S. E. (2003). Testing mediational models with longitudinal data: Questions and tips in the use of structural equation modeling. Journal of Abnormal Psychology, 112, 558-577. http://dx.doi.org/10.1037/0021-843X.112.4.558

Crosby, F. (1976). A model of egoistical relative deprivation. Psychological Review, 83, 85-113. 
http://dx.doi.org/10.1037/0033-295X.83.2.85

Donovan, S.H., Bradley, D.H., \& Shimabukuro, J.O. (2016). What does the gig economy mean for workers? (CRS Report R44365). Washington, DC: Congressional Research Service.

Dumani, S. (2015). Engaging overqualified employees: The role of job and nonwork crafting (unpublished doctoral dissertation). (Available from ProQuest Dissertations and Theses database (UMI No. 3739591).

Edwards J.R. (1991). Person-job fit: A conceptual integration, literature review and methodological critique. In C.L. Cooper and I.T. Robertson (Eds.), International review of industrial/organizational psychology, (Vol. 6, pp. 283-357). London: Wiley.

Edwards, J. R. (1996). An examination of competing versions of the person-environment fit approach to stress. Academy of Management Journal, 39, 292-339. http://dx.doi.org/ $10.2307 / 256782$

Edwards, J. R., Cable, D. M., Williamson, I. O., Lambert, L. S., \& Shipp, A. J. (2006). The phenomenology of fit: Linking the person and environment to the subjective experience of person-environment fit. Journal of Applied Psychology, 91, 802-827. http://dx.doi.org/ $10.1037 / 0021-9010.91 .4 .802$

Edwards, J. R., \& Van Harrison, R. (1993). Job demands and worker health: Three-dimensional reexamination of the relationship between person-environment fit and strain. Journal of Applied Psychology, 78, 628-648. http://dx.doi.org/10.1037/0021-9010.78.4.628

Erdogan, B., Bauer, T. N., Peiro, J., \& Truxillo, D. M. (2011). Overqualified employees: Making The best of a potentially bad situation for individuals and organizations. Industrial and Organizational Psychology, 4, 215-232. http://dx.doi.org/10.1111/j.17549434.2011.01330.x 
Feldman, D. C. (2011). Theoretical frontiers for underemployment research. In D. C. Maynard \& D.C. Feldman (Eds.), Underemployment: Psychological, economic, and social challenges (pp. 277-305). New York, NY: Springer.

Fisher, G. G., Stachowski, A., Infurna, F. J., Faul, J. D., Grosch, J., \& Tetrick, L. E. (2014). Mental work demands, retirement, and longitudinal trajectories of cognitive functioning. Journal of Occupational Health Psychology, 19, 231-242. http://dx.doi.org/ $10.1037 / \mathrm{a} 0035724$

Frey, M. C., \& Detterman, D. K. (2004). Scholastic assessment or g? The relationship between the scholastic assessment test and general cognitive ability. Psychological Science, 15, 373-378. http://dx.doi.org/10.1111/j.0956-7976.2004.00687.x

Friedland, D. S., \& Price, R. H. (2003). Underemployment: Consequences for the health and well-being of workers. American Journal of Community Psychology, 32, 33-45. http://dx.doi.org/10.1023/A:1025638705649

Harari, M. B., Manapragada, A., \& Viswesvaran, C. (2017). Who thinks they're a big fish in a small pond and why does it matter? A meta-analysis of perceived overqualification. Journal of Vocational Behavior, 102, 28-47. http://dx.doi.org/10.1016/j.jvb.2017.06.002

Houkes, I., Janssen, P. P.M., de Jonge, J. and Bakker, A. B. (2003). Specific determinants of intrinsic work motivation, emotional exhaustion and turnover intention: A multisample longitudinal study. Journal of Occupational and Organizational Psychology, 76, 427450. http://dx.doi.org/10.1348/096317903322591578

Hu, J., Erdogan, B., Bauer, T. N., Jiang, K., Liu, S., \& Li, Y. (2015). There are lots of big fish in 
this pond: The role of peer overqualification on task significance, perceived fit, and performance for overqualified employees. Journal of Applied Psychology, 100, 12281238. http://dx.doi.org/10.1037/ap10000008

Hu, L. T., \& Bentler, P. M. (1999). Cutoff criteria for fit indexes in covariance structure analysis: Conventional criteria versus new alternatives. Structural Equation Modeling: A Multidisciplinary Journal, 6, 1-55. http://dx.doi.org/10.1080/10705519909540118

James, L. R., \& Jones, A. P. (1980). Perceived job characteristics and job satisfaction: An examination of reciprocal causation. Personnel Psychology, 33, 97-135. http://dx.doi.org/ 10.1111/j.1744-6570.1980.tb02167.x

Johnson, G. J., \& Johnson, W. R. (1999). Perceived overqualification and health: A longitudinal analysis. The Journal of Social Psychology, 139, 14-28. http://dx.doi.org/10.1080/002245 49909598358

Koenig, K. A., Frey, M. C., \& Detterman, D. K. (2008). ACT and general cognitive ability. Intelligence, 36, 153-160. http://dx.doi.org/10.1016/j.intell.2007.03.005

Kristof- Brown, A. L., Zimmerman, R. D., \& Johnson, E. C. (2005). Consequences of individuals' fit at work: A meta-analysis of person-job, person-organization, persongroup, and person-supervisor fit. Personnel Psychology, 58, 281-342. http://dx.doi.org/ $10.1111 / \mathrm{j} .1744-6570.2005 .00672 . x$

Lee, C. H. (2005). A study of underemployment among self-initiated expatriates. Journal of World Business, 40, 172-187. http://dx.doi.org/10.1016/j.jwb.2005.02.005

Little, T. D., Cunningham, W. A., Shahar, G., \& Widaman, K. F. (2002). To parcel or not to parcel: Exploring the question, weighing the merits. Structural Equation Modeling, 9, 151-173. http://dx.doi.org/10.1207/S15328007SEM0902_1 
Little, T. D., Rhemtulla, M., Gibson, K., \& Schoemann, A. M. (2013). Why the items versus parcels controversy needn't be one. Psychological Methods, 18, 285-300. http://dx.doi. org/10.1037/a0033266

Liu, C., Spector, P., \& Jex, S. (2005). The relation of job control with job strains: A comparison of multiple data sources. Journal of Occupational and Organizational Psychology, 78, 325-336. http://dx.doi.org/10.1348/096317905X26002

Liu, S., Luksyte, A., Zhou, L., Shi, J., \& Wang, M. (2015). Overqualification and counterproductive work behaviors: Examining a moderated mediation model. Journal of Organizational Behavior, 36, 250-271. http://dx.doi.org/10.1002/job.1979

Liu, S., \& Wang, M. (2012). Perceived overqualification: A review and recommendations for research and practice. In P. L. Perrewé, J. Halbesleben, \& C. C. Rosen (Eds.), The role of the economic crisis on occupational stress and well being (Vol. 10, pp.1-42). Bingley, UK: Emerald Group Publishing.

Luksyte, A., \& Spitzmueller, C. Behavioral science approaches to studying underemployment (2011). In D. C. Maynard \& D.C. Feldman (Eds.), Underemployment: Psychological, economic, and social challenges (pp. 35-56). New York, NY: Springer.

Luksyte, A., Spitzmueller, C., \& Maynard, D. C. (2011). Why do overqualified incumbents deviate? Examining multiple mediators. Journal of Occupational Health Psychology, 16, 279-296. http://dx.doi.org/10.1037/a0022709

Maltarich, M. A., Nyberg, A. J., \& Reilly, G. (2010). A conceptual and empirical analysis of the cognitive ability-voluntary turnover relationship. Journal of Applied Psychology, 95, 1058-1070. http://dx.doi.org/10.1037/a0020331

Maltarich, M. A., Reilly, G., \& Nyberg, A. J. (2011). Objective and subjective overqualification: 
Distinctions, relationships, and a place for each in the literature. Industrial and Organizational Psychology, 4, 236-239. http://dx.doi.org/10.1111/j.1754-9434. 2011. 01332.X

Maynard, D. C., Brondolo, E. M., Connelly, C. E., \& Sauer, C. E. (2015). I'm too good for this job: Narcissism's role in the experience of overqualification. Applied Psychology, 64, 208-232. http://dx.doi.org/10.1111/apps.12031

Maynard, D. C., Joseph, T. A., \& Maynard, A. M. (2006). Underemployment, job attitudes, and turnover intentions. Journal of Organizational Behavior, 27, 509-536. http://dx.doi.org/ 10.1002/job.389

Maynard, D. C., \& Parfyonova, N. M. (2013). Perceived overqualification and withdrawal behaviours: Examining the roles of job attitudes and work values. Journal of Occupational and Organizational Psychology, 86(3), 435-455. http://dx.doi.org/ 10.1111/joop.12006

Maynard, D. C., Taylor, E. B., \& Hakel, M. D. (2009). Applicant overqualification: Perceptions, predictions, and policies of hiring managers. In O. T.Chen (Ed.), Organizational behavior and dynamics (pp. 13-38). Hauppauge, NY: Nova Science.

McKee-Ryan, F. M., \& Harvey, J. (2011). "I have a job, but...”: A review of underemployment. Journal of Management, 37, 962-996. http://dx.doi.org/10.1177/0149206311398134

McKee-Ryan, F. M., Virick, M., Prussia, G. E., Harvey, J., \& Lilly, J. D. (2009). Life after the layoff: Getting a job worth keeping. Journal of Organizational Behavior, 30, 561-580. http://dx.doi.org/10.1002/job.566

Muthén, L.K. and Muthén, B.O. (1998-2012). Mplus User's Guide. Seventh Edition. Los Angeles, CA: Muthén \& Muthén. 
Nabi, G. R. (2003). Graduate employment and underemployment: opportunity for skill use and career experiences amongst recent business graduates. Education+ Training, 45, 371382. http://dx.doi.org/10.1108/00400910310499947

Ryan, R. M. (1995). Psychological needs and the facilitation of integrative processes. Journal of Personality, 63, 397-427. http://dx.doi.org/10.1111/j.1467-6494.1995.tb00501.x

Satorra, A., \& Bentler, P. M. (2001). A scaled difference chi-square test statistic for moment structure analysis. Psychometrika, 66, 507-514. http://dx.doi.org/10.1007/BF02296192

Spector, P. E., \& Jex, S. M. (1991). Relations of job characteristics from multiple data sources with employee affect, absence, turnover intentions, and health. Journal of Applied Psychology, 76, 46-53. http://dx.doi.org/10.1037/0021-9010.76.1.46

Teicher Khadaroo, S. (2015, September 3). As states change use of SAT and ACT, disadvantaged students get boost. Retrieved from http://www.csmonitor.com/USA/ Education/2015/0903/As-states-change-use-of-SAT-and-ACT-disadvantaged-studentsget-boost

U.S. Bureau of Labor Statistics (2016). https://www.bls.gov/emp/ep_nem_definitions.htm Verhaest, D., \& Omey, E. (2006). The impact of overeducation and its measurement. Social Indicators Research, 77, 419-448. http://dx.doi.org/10.1007/s11205-005-4276-6

Williams, E. J. (1959). The comparison of regression variables. Journal of the Royal Statistical Society (Series B), 21, 396-399.

Wu, W., Selig, J.P., \& Little, T.D. (2013). Longitudinal data analysis. In T.D. Little (Ed.), The Oxford handbook of quantitative methods (Statistical analysis, Vol. 2, pp. 387-410). New York, NY: Oxford University Press. 
Table 1. Descriptive statistics and intercorrelations among Study 1 variables.

\begin{tabular}{|c|c|c|c|c|c|c|c|c|c|}
\hline & $N$ & $M$ & $S D$ & 1 & 2 & 3 & 4 & 5 & 6 \\
\hline 1. Objective Overqualification & 111 & 0.09 & 2.47 & - & & & & & \\
\hline 2. Overeducation & 158 & 2.09 & 2.24 & $.84^{* *}$ & & & & & \\
\hline 3. Skill overqualification & 156 & 30.81 & 22.01 & $.77^{* *}$ & & & & & \\
\hline 4. Cognitive ability overqualification & 112 & 0.86 & 1.08 & $.82^{* *}$ & & & - & & \\
\hline 5. Perceived Overqualification & 162 & 3.49 & 1.00 & & & .32 & $.34^{* *}$ & $(.91)$ & \\
\hline 6. Job Satisfaction & 162 & 3.51 & 0.78 & & 14 & .04 & -.12 & $-.38^{* *}$ & $(.91)$ \\
\hline
\end{tabular}

Notes: ${ }^{* *} p<.01,{ }^{*} p<.05$. Reliabilities are on the diagonal. Objective overqualification was measured as the sum of samplestandardized cognitive ability overqualification, skill overqualification, and overeducation scores. 
Table 2. Descriptive statistics and intercorrelations among Study 2 variables.

\begin{tabular}{|c|c|c|c|c|c|c|c|c|c|}
\hline & $N$ & $M$ & $S D$ & 1 & 2 & 3 & 4 & 5 & 6 \\
\hline 1. Perceived overqualification (t1) & 558 & 2.96 & 1.01 & $(.92)$ & & & & & \\
\hline 2. Perceived overqualification (t2) & 230 & 3.13 & 1.02 & $.89^{* *}$ & $(.93)$ & & & & \\
\hline 3. Perceived overqualification ( $\mathrm{t} 3)$ & 155 & 3.19 & 1.04 & $.89^{* *}$ & $.94^{* *}$ & $(.94)$ & & & \\
\hline 4. Job satisfaction (t1) & 537 & 4.00 & 0.88 & $-.45^{* *}$ & $-.41^{* *}$ & & & & \\
\hline 5. Job satisfaction (t2) & 229 & 3.94 & 0.89 & $-.34^{* *}$ & $-.41^{* *}$ & & .77 & $(.86)$ & \\
\hline 6. Job satisfaction (t3) & 155 & 3.84 & 0.94 & $-.30^{* *}$ & $-.32^{* *}$ & $-.33^{* *}$ & $.76^{* *}$ & $.81^{* *}$ & $(.84)$ \\
\hline
\end{tabular}

Notes. ${ }^{* *} p<.001$. The time point of measurement is noted in parentheses. Reliabilities are on the diagonal. 


\section{OVERQUALIFICATION}

Figure 1. Path estimates from the mediation model in Study 1.

Figure 2. Path estimates from the cross-lagged panel model in Study 2.

Highlights

- Perceived OQ is prevalent in research, but objective OQ is critical in practice.

- Objective OQ and job satisfaction independently predict perceived OQ.

- Perceived OQ is likely not a good proxy for objective OQ.

- Job satisfaction is a likely a predictor, not an outcome, of perceived OQ. 


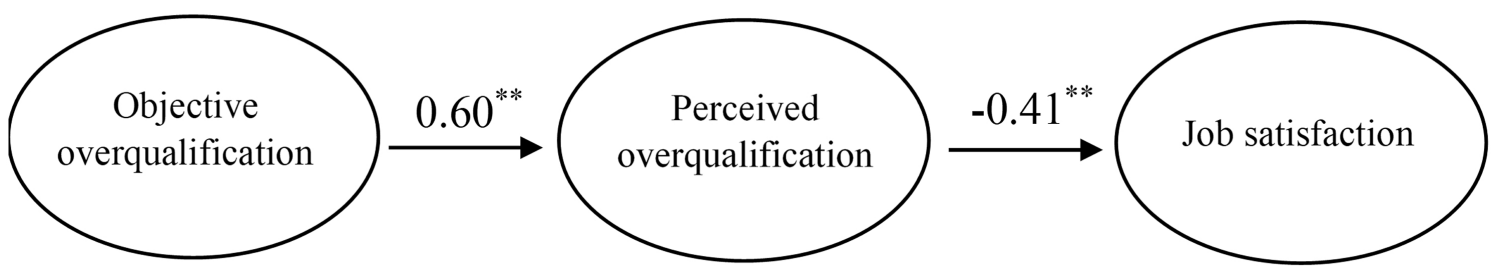

Notes. ${ }^{* *} p<.001$. Standardized coefficients are reported.

Figure 1 


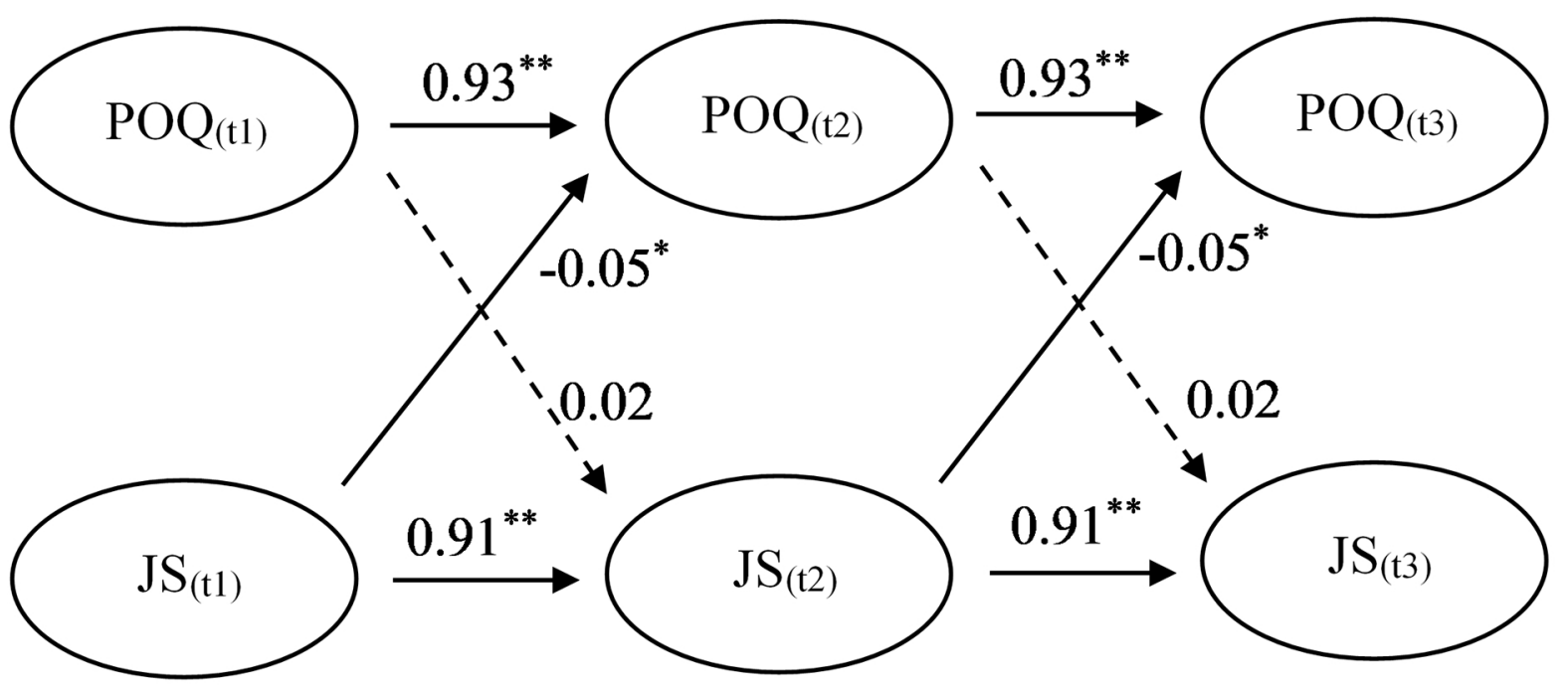

Notes. ${ }^{* *} p<.001,{ }^{*} p<.05$. Due to slight variations in the standardized coefficients across time points (as a consequence of the equality constraints being imposed on unstandardized coefficients), we report the mean of standardized coefficients. $\mathrm{POQ}=$ perceived overqualification, $\mathrm{JS}=$ job satisfaction. The time point of measurement is noted in parentheses. 